\title{
Usefulness of a needleless suture technique for midline laparotomy wound dehiscence: a case report
}

\author{
Da Yeon Lee ${ }^{1}$, Pil Young Jung ${ }^{2}$ \\ ${ }^{1}$ Department of emergency medicine, Dongguk University Ilsan Hospital, Goyang, ${ }^{2}$ Department \\ of Surgery, Yonsei University Wonju College of Medicine, Wonju Severance Christian Hospital, \\ Wonju, Korea
}

Received May 10, 2021

Revised August 10, 2021

Accepted August 26, 2021

Correspondence to

Pil Young Jung

Department of Surgery, Yonsei

University Wonju College of Medicine,

20 Ilsan-ro, Wonju 26426, Korea

Tel: +82-33-741-0882

Fax: +82-33-741-0574

E-mail: surgery4trauma@yonsei.ac.kr
Surgical wound dehiscence after a laparotomy is a serious complication, and it presents the mechanical wound healing failure of surgical incisions. Since the development of needleless suture techniques, there have been attempts to use a needleless suture for wounds from several surgery types. Recently, many studies have shown that a needleless suture technique leads to good wound healing results. It is rapid, cost effective, can minimize ventilator dependency, and is well tolerated by patients. Here, we report a case of a patient who received a needleless suture technique for midline laparotomy wound dehiscence.

Key Words: Laparotomy, Postoperative complications, Surgical wound dehiscence, Suture techniques

\section{Introduction}

Surgical wound dehiscence after a laparotomy can occur in early or late postoperative period, and it involves a different portion of the incision. If a dehiscence only involves a portion of the incision, it is called partial dehiscence. If it involves the entire incision, it is called complete fascial dehiscence (4).

Post-laparotomy wound dehiscence occurs in $0.25 \%-3 \%$ of patients who underwent laparotomy.

The common risk factors that increase the incidence of wound dehiscence include old age, male, emergency surgery, wound infection, and sepsis (5). The management of dehisced wounds includes immediate wound exploration if the bowel is protruding from the wound. The mortality rate associated with a complete fascial dehiscence was reported to be $10 \%(6,7)$.

In Germany, professor H.Y. Kaessman developed a skin wound-closing device made of zippers in 1989. Several products of the same concept were also developed and used. There were also attempts to use a needleless suture technique on surgical wounds of several different kinds of surgery (8).

Herein, we report a case of a patient who received a needleless suture for midline laparotomy wound dehiscence in addition to the primary closure of surgical wounds.

(c)This is an Open Access article distributed under the terms of the Creative Commons Attribution Non-Commercial License (http://creativecommons.org/licenses/by-nc/4.0) which permits unrestricted noncommercial use, distribution, and reproduction in any medium, provided the original work is properly cited.

Copyright (C) 2021 Korean Association for Research, Procedures and Education on Trauma. All rights reserved. 


\section{Case presentation}

A 78-year-old male was transferred to our trauma center after a traffic accident. His chest and abdomen were bumped against a steering wheel $6 \mathrm{~h}$ before he was transferred to our center. He complained of chest wall and abdominal pain. The initial vital signs were a blood pressure of 143/68 $\mathrm{mmHg}$, a heart rate of 83 beats/min, a respiratory rate of 16 breaths/min, and a body temperature of $35.1^{\circ} \mathrm{C}$. Chest and abdominopelvic computed tomography scans were taken to evaluate the damages in intra-abdominal organs. Free air in both subphrenic spaces that suggests bowel injury was confirmed as a result (Fig. 1).

An emergency laparotomy was performed under the suspicion of a small bowel perforation. Since $9 \mathrm{~h}$ already passed after his injury, there was a large amount of dirty fluid in the abdominal cavity. The small bowel was gener-

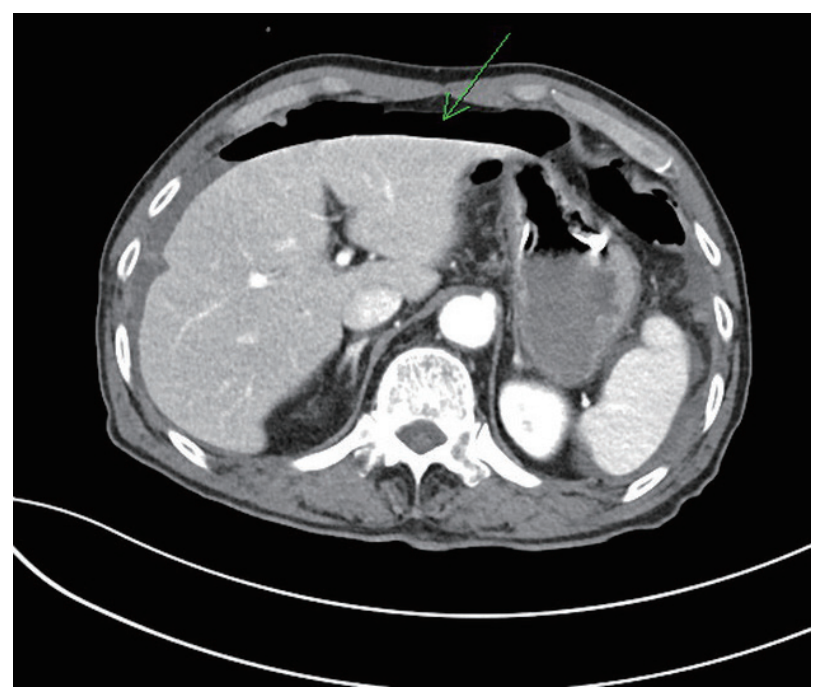

Fig. 1. Free air of both subphrenic spaces.

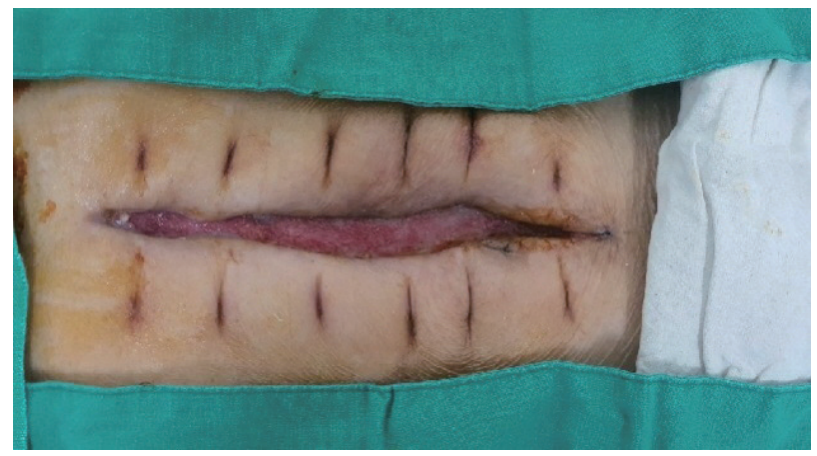

Fig. 2. Wound dehiscence of the patient. ally inflamed, with a perforation located in the jejunum, $50 \mathrm{~cm}$ distal to the ligament of Treitz. A primary repair of the perforation was done. Since there were no other injuries, the operation was terminated after a massive irrigation and Hemovac (Zimmer Biomet, Warsaw, Indiana, United States) insertion.

After the emergency operation, the surgical wound dehisced on postoperative day (POD) 15. Despite the saline-soaked dressing and gradual improvement of the granulation tissue, the abdominal incision was not completely closed until POD 38 (Fig. 2). However, it was only a partial dehiscence, and the bowel was not protruding. Due to a recently diagnosed atrial fibrillation upon admission, apixaban was given from POD 18. Considering the administration of an anticoagulant and his old age, we decided not to surgically reopen the wound to debride the infected tissue. Therefore, an approximation of the wound dehiscence was done with a 14-cm Lichen Needleless Suture (Sichuan Lichen Medical and Pharmaceutical Technology, Chengdu, Sichuan, China) (Fig. 3). The device consisted of two bands to which a locking ring was attached with a medical adhesive tape, which can be tensioned by adjusting the length of the thorn bandage.

Two weeks after applying the needleless suture device, the device was removed to check the wound on POD 32. Compared to the wound condition prior to the treatment, only a small exposure of dermal separation remained, without the exposure of subcutaneous tissues. The patient was transferred to a local hospital for a continuous wound management on POD 45.

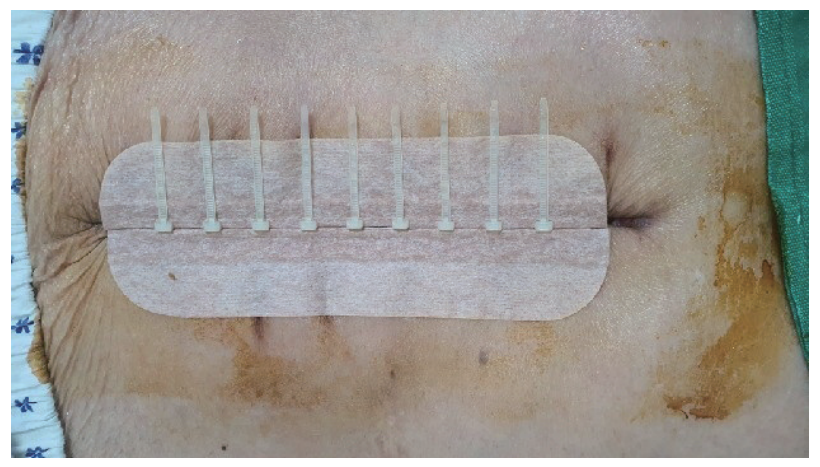

Fig. 3. Approximation of the wound dehiscence with a needleless suture. 


\section{Discussion}

Surgical wound dehiscence remains a serious complication with a mortality rate of $10 \%(6,7)$. The typical management of post-laparotomy wound dehiscence includes a wet dressing and wound re-opening to debride the infected tissues. Patients with wound dehiscence, as in this case, are highly likely to have risk factors to reopen the wound and debride the infected tissues. Therefore, it may be reasonable to look for other management options other than reoperation, unless it is inevitable (3).

In this case, post-laparotomy wound dehiscence was treated without evisceration. The patient was an old male who had many underlying diseases, including hypertension and atrial fibrillation. In addition, $9 \mathrm{~h}$ of prolonged injury prior to surgery worsened the inflammation of the small bowel, leading to a severe adhesion. Under this assessment, a needleless suture technique was selected instead of wound re-opening to debride the infected tissues.

The needleless suture technique is the latest non-needle, non-invasive surface suture technique that reduces the wound closure time and ventilator dependency. It is also cost effective, has cosmetic advantages, and well tolerated by patients. Therefore, it can increase the patient's satisfaction, with good wound healing results $(9,10)$.

Based on this case, the needleless suture technique can be used for surgical wound dehiscence and as the primary closure method. It can be an atraumatic and patient-favorable treatment option for wound dehiscence when an immediate operation is not required or when a patient is intolerable to surgery.

\section{Conflict of interest}

No potential conflict of interest relevant to this article was reported.

\section{References}

1. Carli AV, Spiro S, Barlow BT, Haas SB. Using a non-invasive secure skin closure following total knee arthroplasty leads to fewer wound complications and no patient home care visits compared to surgical staples. Knee. 2017;24(5):1221-6.

2. Brega-Massone PP, Lequaglie C, Magnani B, Cataldo I. A new proposal of skin-closure system for median sternotomy: usefulness and cosmetic results analysis of MEDIZIP Surgical Zipper in neoplastic immuno-compromised patients. J Surg Oncol. 2003;84(4): 249-54.

3. Spiliotis J, Tsiveriotis K, Datsis AD, Vaxevanidou A, Zacharis G, Giafis K, et al. Wound dehiscence: is still a problem in the 21st century: a retrospective study. World J Emerg Surg. 2009;4:12.

4. Jason S. Complications of abdominal surgical incisions. UpToDate. 2020. Available from: https://www. uptodate.com/contents/complications-of-abdominalsurgical-incisions? search=wound\%20dehiscence \&source=search_result\&selectedTitle $=2 \sim 123 \&$ usage _ type $=$ default\&display_rank=2\#H1.

5. Pavlidis TE, Galatianos IN, Papaziogas BT, Lazaridis CN, Atmatzidis KS, Makris JG, et al. Complete Dehiscence of the Abdominal Wound and Incriminating Factors. Eur J Surg. 2001; 167:351.

6. Jyrki TM, Heikki K, Tatu J, Seppo L. Factors influencing wound dehiscence after midline laparotomy. Am J Surg. 1995;170(4):387-90.

7. Waqar SH, Malik ZI, Razzaq A, Abdullah MT, Shaima A, Zahid MA. Frequency and risk factors for wound dehiscence/burst abdomen in midline laparotomies. Journal of Ayub Medical College, Abbottabad. 2005; 17(4):70-3.

8. John EO, Ewan A, Dorcas SO. Outcome of surgical zipper technique. Journal of the National Medical Association. 2006;98(1):83-5

9. Yuki T, Takashi M, Yuji N, Shuichi Y, Akihiro S, Kagami M. Randomized study of a new noninvasive skin closure device for use after congenital heart operations. Ann Thorac Surg. 2016;102:1368-74

10. Garrett LW, Patrick C, Gilles H, Marvin JW, Jonathan LM. The open abdomen: the Marlex mesh and zipper technique: a method of managing intraperitoneal infection. The Surgical Clinics of North America. 1988;68(1):25-40 